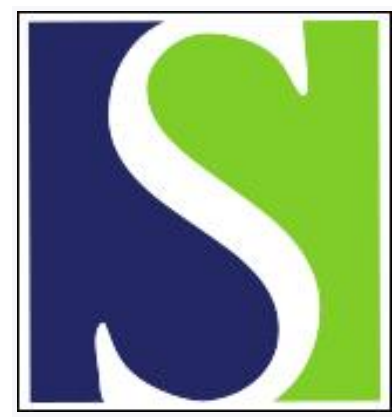

Scand J Work Environ Health 2013;39(4):390-400

https://doi.org/10.5271/sjweh.3357

Published online: 14 Mar 2013, Issue date: 01 Jul 2013

The effect of work-related sustained trapezius muscle activity on the development of neck and shoulder pain among young adults

by Hanvold TN, Wærsted M, Mengshoel AM, Bjertness E, Stigum H, Twisk J, Veiersted KB

The results indicate that sustained trapezius muscle activity with periods of more than 4 minutes duration for more than half of the working day, increases the rate of neck and shoulder pain in a 2.5-year period. This implicates the importance of reducing the lengths of periods with sustained muscle activity at work.

Affiliation: National Institute of Occupational Health, PO Box 8149 Dep, 0033 Oslo, Norway. tno@stami.no

Refers to the following texts of the Journal: 1993;19(4):277-283 1993;19(4):284-290 2009;35(2):85-95 2001;27(1):41-48

The following article refers to this text: 2015;41(3):234-246

Key terms: electromyography; EMG; muscle activity; musculoskeletal disorder; sustained muscle activity; sustained trapezius muscle activity; trapezius muscle; workload; young adult; young worker

This article in PubMed: www.ncbi.nlm.nih.gov/pubmed/23494255 


\title{
The effect of work-related sustained trapezius muscle activity on the development of neck and shoulder pain among young adults
}

\author{
by Therese N Hanvold, MSc, ${ }^{1}$ Morten Wærsted, PhD, ${ }^{1}$ Anne Marit Mengshoel, PhD, ${ }^{2}$ Espen Bjertness, \\ PhD, ${ }^{2}$ Hein Stigum, PhD ,2, 3 Jos Twisk, PhD, ${ }^{4}$ Kaj Bo Veiersted, PhD ${ }^{1}$
}

\begin{abstract}
Hanvold TN, Wærsted M, Mengshoel AM, Bjertness E, Stigum H, Twisk J, Veiersted KB. The effect of work-related sustained trapezius muscle activity on the development of neck and shoulder pain among young adults. Scand $\mathrm{J}$ Work Environ Health. 2013:39(4):390-400. doi:10.5271/sjweh.3357
\end{abstract}

\begin{abstract}
Objective This study aimed to evaluate if sustained trapezius muscle activity predicts neck and shoulder pain over a 2.5 -year period.

Methods Forty young adults ( 15 hairdressers, 14 electricians, 5 students and 6 with various work) were followed during their first years of working life. Self-reported neck and shoulder pain during the last four weeks was assessed seven times over the observational period. Upper-trapezius muscle activity was measured during a full working day by bilateral surface electromyography (EMG) at baseline (winter 2006/7). Sustained trapezius muscle activity was defined as continuous muscle activity with amplitude $>0.5 \% \mathrm{EMG}_{\max }$ lasting $>4$ minutes. The relative time of sustained muscle activity during the working day was calculated and further classified into low $(0-29 \%)$, moderate (30-49\%) and high (50-100\%) level groups.
\end{abstract}

Results Generalized estimating equations (GEE), adjusted for time, gender, mechanical workload, controlover-work intensity, physical activity, tobacco use, and prior neck and shoulder pain, showed that participants with a high level of sustained muscle activity had a rate of neck and shoulder pain three times higher than the low level group during a 2.5 -year period. The association was strongest at the same time and shortly after the EMG measurement, indicating a time-lag of $\leq 6$ months.

Conclusion The results support the hypothesis that sustained trapezius muscle activity is associated with neck and shoulder pain. This association was strongest analyzing cross-sectional and short-term effects.

Key terms electromyography; EMG; musculoskeletal disorder; workload; young worker.

Neck and shoulder disorders are a considerable health problem in the working population with prevalence rates of $\geq 30 \%(1,2)$. Pain in this region is common also among young adults in their first years of working life (3). Work-related neck and shoulder pain represents suffering for the individual and is a considerable economic challenge for society.

The etiology of work-related neck and shoulder pain has been extensively examined, however the causes are still unclear and regarded as complex and multifactorial (4). Biomechanical and psychosocial workplace factors as well as individual risk factors have all been related to neck and shoulder pain (5-8). The deleteri- ous effect of sustained activity pattern in the trapezius muscle (which is the occurrence of continuous muscle activation without interruptions) has been proposed as a common mechanism for explaining neck and shoulder pain (9). Veiersted and co-workers (10) found that a low frequency of interruptions in trapezius muscle activity during repetitive tasks was associated with future development of neck pain. More recent studies have shown a correlation between trapezius muscle activation and pain. In a cross-sectional study, Szeto et al (11) found that those office workers with high levels of neck and shoulder pain had higher trapezius muscle activity compared to office workers with lower pain levels. A

1 National Institute of Occupational Health, Oslo, Norway.

2 University of Oslo, Institute of Health and Society, Oslo, Norway.

3 Norwegian Institute of Public Health, Oslo, Norway.

4 VU University Medical Center, Amsterdam, The Netherlands.

Correspondence to: Therese Nordberg Hanvold, National Institute of Occupational Health, PO Box 8149 Dep, 0033 Oslo, Norway. [E-mail: tno@stami.no] 
longitudinal study on forest machine operators found that a higher frequency of episodes with sustained trapezius muscle activity lasting for $\geq 8$ minutes was related to future reports of neck pain (12). These studies suggest that reduced muscle rest or sustained muscle activity may be essential factors leading to neck and shoulder pain. In contrast, others have proposed that either pain leads to decreased muscle activity (13) or there is no association between low-level trapezius muscle activity and pain (14-17).

Since there is no consensus concerning trapezius muscle activity and its relation to neck and shoulder pain, we have used a longitudinal design for this study with frequent measurements of neck and shoulder pain to evaluate the long-term effects and time-lag, in addition to cross-sectional effects and reverse relationship, of sustained muscle activity. We studied young adults in order to investigate the development of work-related pain in the first years of working life when participants have had no or little exposure from earlier work. This is in contrast to most previous studies on this topic that have investigated middle-aged or older workers. Moreover, only a few prior studies have applied a longitudinal design.

The hypothesis of this study postulates that sustained trapezius muscle activity pattern at work predicts neck and shoulder pain over the following 2.5 years.

\section{Methods}

\section{Study design}

In this prospective study, 40 young adults were followed over a 3.5-year period (2006-2009). Baseline measurement occurred during the winter of 2006/2007, when a recording of each participant's upper-trapezius muscle activity was taken during a full working day. The same day, all study participants completed a questionnaire. Over the following 2.5-year period, the participants completed questionnaires approximately every $4^{\text {th }}$ month providing information on pain and other covariate variables. Over a 1-year period prior to baseline (2006), questionnaires on neck and shoulder pain were collected on three occasions and used as a covariate. The study design is illustrated in table 1.

\section{Study sample}

The 40 participants ( 23 women and 17 men) were a subsample from a cohort followed from 2002 and consisting of 420 technical school students, representing student hairdressers, student electricians, and art/media/ design students (18). Of the 420 subjects, 140 were not contacted because they had withdrawn from the original study or had moved away from the Oslo region. Telephone contact was attempted with the remaining 280 subjects, and a total of 156 were reached and asked if they would take part in the one-day field registration. Of these, 111 subjects refused due to, for example, problems obtaining permission from their employer or not being interested, leaving 45 subjects for inclusion in the study. Two of these cancelled their appointments, and data of three subjects were excluded because of technical defects in the electromyography (EMG) registration, leaving data on a total of 40 participants. The participants had different occupations at the time of the muscle activity measurement: 15 females were hairdressers, 14 males were electricians, 5 females were students, and 3 females and 3 males had other occupations, such as working in the retail business or kindergarten. Table 2 presents a further overview of the study group characteristics. The study group ( $\mathrm{N}=40)$ had significantly lower tobacco use prevalence at baseline than the remaining cohort $(\mathrm{N}=380, \mathrm{P}=0.03)$. Otherwise there were no significant differences between the study groups and the rest of the cohort for the variables listed in table 2 .

\section{Upper-trapezius muscle activity}

Upper-trapezius muscle activity was evaluated by bilateral surface EMG, recorded with $6 \mathrm{~mm}$ diameter, bipolar electrodes (E-10-VS, Medicotest A/S, Ølstykke, Denmark). The electrodes were placed with a $20 \mathrm{~mm}$ inter-electrode distance parallel to the underlying muscle fibers in standardized positions $(19,20)$. The root mean square (RMS) value was calculated for epochs of oneeighth of a second, and the recorded noise level was subtracted. The signal was then processed through a rectangular moving average filter of 1.625 -second length, giving an RMS window length of approximately 1.6 seconds. The data was controlled for movement artifacts and electromagnetic interference as described by Hansson and co-workers (21). This controlling procedure did not identify any artifacts or interference and therefore no parts of the recordings were excluded.

Applying a manual resistance against which the arm was abducted $90^{\circ}$ in the scapular plane (21), the investigator normalized the full working day EMG recording in percent of the $\mathrm{EMG}_{\max }$ of standardized maximum muscle contractions. The mean EMG recording length was 6 hours and 22 minutes (range 3 hour 39 minutes- 8 hours 37 minutes). Sustained trapezius muscle activity was defined as the relative time (\% of time during the full working day) with activity $>0.5 \% \mathrm{EMG}_{\max }$ continuously for $>4$ minutes. This duration was chosen on the basis of a recent methodological study on the effects of EMG data processing procedures where it was found that 4 minutes was one of the preferable measures (22). 
Table 1. Study design (2006-2009) and missing data information from 40 young adults. [Q=questionnaire; missing=number of nonresponders; "."=missing by design]

\begin{tabular}{|c|c|c|c|c|c|c|c|c|}
\hline & \multirow{2}{*}{$\frac{2006}{Q_{\text {prior }}{ }^{\mathrm{a}}}$} & \multicolumn{2}{|c|}{$2006 / 2007$} & \multirow[b]{2}{*}{ Q3 } & \multicolumn{2}{|l|}{2008} & \multicolumn{2}{|c|}{2009} \\
\hline & & Q1 & Q2 & & Q4 & Q5 & Q6 & Q7 \\
\hline \multicolumn{9}{|c|}{ Neck/shoulder pain } \\
\hline Missing & $2 / 10 / 9$ & 0 & 8 & 5 & 10 & 17 & 11 & 6 \\
\hline \multicolumn{9}{|c|}{ Mechanical workload } \\
\hline Missing & & 2 & & . & 14 & . & . & 10 \\
\hline \multicolumn{9}{|c|}{ Tobacco use } \\
\hline Missing & & 0 & & . & 10 & . & . & 6 \\
\hline \multicolumn{9}{|c|}{ Control over work intensity } \\
\hline Missing & & 0 & . & . & 10 & . & . & 7 \\
\hline \multicolumn{9}{|c|}{ Physical activity } \\
\hline Missing & & 0 & . & . & 10 & . & . & 6 \\
\hline
\end{tabular}

a The mean of three questionnaires on neck and shoulder pain to register "prior pain".

An earlier study using similar episodes with sustained muscle activity (23) and the distribution of our data were also both important when choosing the exposure measure. In order to check how appropriate the choice of a 4-minute duration threshold was, a control analysis was conducted with duration thresholds of $>2,>6,>8,>10$, and $>15$ minutes, as well as with no demand on duration (ie, including all 1.6-second RMS windows $>0.5 \%$ $\left.\mathrm{EMG}_{\max }\right)$. Widely used EMG measures such as static muscle activity $\left(10^{\text {th }}\right.$ percentile of the amplitude distribution) $(22,24)$ and muscle rest (proportion of total time with $E M G$ activity $<0.5 \%$ of $\left.E M G_{\max }\right)(22,25)$ were also analyzed. For these measures, we used a 0.13 -second RMS window, which is in line with earlier studies (22, 24, 25). The EMG recording was done bilaterally and the relative time of sustained muscle activity was calculated for each side before a mean from the right and left EMG recording was used in the analyses. The relative time of sustained muscle activity during a full working day was divided into three approximately equally sized groups: (i) low $(0-29 \%)$, (ii) moderate (30-49\%), and (iii) high $(50-100 \%)$ level of sustained trapezius muscle activity.

\section{Questionnaires}

Assessments of neck and shoulder pain were obtained approximately every $4^{\text {th }}$ month over the follow-up period (2006/7-2009), meaning that this information was given in all seven questionnaires during the 2.5-year follow-up. Prior neck and shoulder pain was collected from three questionnaires over a 1-year period prior to the baseline EMG measurement in 2006. The mean of the three neck and shoulder pain index scores was used. Questions on control over work intensity, mechanical workload, physical activity, and tobacco use were recorded approximately every year, giving information in three of the seven questionnaires. This is illustrated in detail in table 1.

Neck and shoulder pain. The participants reported their experienced neck and shoulder pain over the last four weeks (26), reporting both pain intensity on a scale of $0-3$ (no $=0$, little $=1$, moderate $=2$, and severe $=3$ ) and duration in days on a scale of $1-4(1-5=1,6-10=2$, $11-14=3$, and $15-28=4$ ). A mannequin drawing was used to give a full understanding of the neck and shoulder region (27). A pain index was calculated by multiplying pain intensity (0-3) and duration (1-4), giving a pain index ranging from $0-12$. The reliability of this method has been found to be acceptable based on testing the correlation between the questionnaire and a medical examination (Spearman's correlation coefficient 0.73 ) (28). Long-lasting or severe neck and shoulder pain was defined as an index score of $\geq 4$ (meaning that the subject either reported little pain for $>2$ weeks or moderate/ severe pain for $\geq 6$ days over the last 4 weeks).

Covariates. The participants' working status was monitored in all seven questionnaires during the follow-up period, to detect possible changes from one profession to another or a change from work to studying or other possible status changes. The participants were asked about their perceived control-over-work intensity. Two questions were used to evaluate this: "Can you set your own work pace?" and "Can you determine the lengths of your own breaks?" The questions had 5 response alternatives ranging from $0=$ never/seldom to $4=$ often/very often (29). The mean of the response on these two questions equalled the score on control-over-work intensity. A total of 12 questions were used to assess the work-related mechanical exposure (MI2) (30). The participants were asked whether their work involved or required repetitive movements (one question), precision movements (one question), manual material handling (two questions), vibration (one question), and body postures (seven questions) such as working with their arms elevated or their back twisted or bent forward. The response alternatives were: $0=$ nothing/hardly nothing, $1=$ somewhat, or $2=\mathrm{a}$ great deal. On the basis of the 12 questions, an index was calculated ranging from 0-24 (30). One question 
measured physical activity level during leisure time. The participants were asked how often they performed activities that led to increased heart rate and shortness of breath. The question had 7 response categories ranging from $0=$ never to $6=$ everyday (31). The participants were also asked about their smoking and snuff habits. If they either were smokers or used snuff daily or occasionally they were characterized as tobacco users.

\section{Missing data and imputation procedures}

In our study, some of the time-varying variables were not assessed in all seven questionnaires during the follow-up period and thus were "missing by design" (mechanical workload, tobacco use, control over work intensity, and physical activity). Missing data also resulted when the participants did not answer $\geq 1$ of the questionnaires (unit non-responders) or did not complete single items in a questionnaire (item non-responders). The total amount of missing values from non-responders in each questionnaire ranged from $\mathrm{N}=2(5 \%)$ to $\mathrm{N}=17(42 \%)$ (table 1$)$. To handle the missing data, multiple imputations were done by using a longitudinal regression model that took into account both the clustering in data (multiple observations per individual) and the time trends for the whole group (32). On the basis of five imputed datasets, one average estimate was calculated on the associations (33). A multiple imputation procedure of missing data was done to reduce bias and make use of all the data collected (34).

\section{Data analysis and statistics}

Both STATA, version 11.0 (StataCorp, College Station, TX, USA) and the Statistical Package for Social Sciences, version 18.0 (SPSS Institute, Chicago, IL, USA) were used for the statistical analyses. Cross-sectional differences in pain and background variables were assessed using the independent-samples Mann-Whitney U test. Kruskal Wallis test was used to analyze the three levels of sustained muscle activity and pain while Spearman's rank correlation was used in the calculation of the continuous muscle activity variable $(0-100 \%)$ and pain. A time-lag of pain reports approximately every four months was employed to analyze the time that elapses between the muscle activity exposure and neck or shoulder pain, and generalized estimating equations (GEE) analysis was conducted to evaluate the time-lag and the longitudinal association between sustained muscle activity and pain. This model takes into account the correlation between the repeated measurements within the individual $(35,36)$. A negative binomial GEE analysis was used due to over dispersion in the discrete outcome variable. Incidence rate ratio (IRR) with corresponding $95 \%$ confidence intervals $(95 \% \mathrm{CI})$ were reported for the effect estimates. In all negative binomial GEE analysis, an exchangeable correlations structure was used. Because of the gender difference in effect of pain over time, the univariate and multivariate analyses were done for the whole group and stratified by gender. The study had a relatively small number of subjects $(\mathrm{N}=40)$. However, when incorporating the intraclass correlation coefficient $(\mathrm{rho}=0.315$ ) of the outcome variable and the number of repeated measurements ( 7 repeated measures), the effective sample size was calculated to be $\mathrm{N}=126$. This effective sample size increased the power of the study and allowed a multivariable model with several covariate variables. The multivariate analyses were adjusted for time, mechanical workload, control over work intensity, physical activity, tobacco use, prior pain and gender.

\section{Ethics}

The Regional Committee for Medical Research Ethics and the Norwegian Data Inspectorate approved the study. Written consent was obtained from the participants at the establishment of the original cohort in 2002. In addition, a written parental consent was obtained for the participants in the cohort who were $<18$ years in 2002 .

\section{Results}

\section{Pain and muscle activity at baseline}

Of the 40 participants, 17 (42.5\%) reported neck and shoulder pain at baseline and, of these, 4 (10\%) reported long lasting or severe pain. No significant difference was found between gender and reported neck and shoulder pain $(\mathrm{P}=0.07)$. Differences in pain between the four occupational groups were found $(\mathrm{P}=0.03)$. Hairdressers had the highest median pain of 1 (range $0-8$ ). In all the other occupational groups, more than half reported no neck or shoulder pain (median 0, not shown in table). Differences in muscle activity between the occupational groups were also found $(\mathrm{P}=0.001)$. Hairdressers had a median of $52 \%$ of the working day with sustained muscle activity (range 24-91\%), electricians 33\% (range $17-82 \%$ ), various jobs $27 \%$ (range $6-42 \%$ ) and students $10 \%$ (range $2-49 \%$ ).

The cross-sectional analyses showed differences in neck and shoulder pain between the three muscle activity groups $(\mathrm{P}<0.001)$. The group with high-level muscle activity reported the highest median pain compared to the low and moderate level group. The relative time of sustained muscle activity $(0-100 \%)$ also showed a significant cross-sectional correlation with pain (Spearman`s correlation: 0.21, $\mathrm{P}<0.001$ ). No 
significant differences were found between the three groups and other background variables at baseline (see table $2 \mathrm{a} / \mathrm{b})$.

\section{Prior pain and muscle activity}

Of the 40 participants, 23 (57.5\%) had prior neck and shoulder pain (reported in the year prior to baseline) and, of these, $15(65 \%)$ also reported neck and shoulder pain at baseline, giving a significant correlation between prior pain and pain reported at baseline (Spearman's correlation: $0.58, \mathrm{P}<0.001)$. Analyses on reverse relationship showed a non-significant correlation between relative time of sustained muscle activity $(0-100 \%)$ and prior pain (Spearman's correlation: $0.03, \mathrm{P}=0.37$ ).

\section{Pain over time}

Neck and shoulder pain was found to be fairly stable over time on a group level, showing no significant effect of time ( $\mathrm{P}=0.68)$. The prevalence of neck and shoulder pain varied $26-56 \%$ during the 2.5 -year period. In the same period, between 0-17.5\% reported long-lasting or severe neck and shoulder pain. Even if the betweensubject neck and shoulder pain was found stable over time on a group level, a large within-subject pain variability was found over the same period. Figure 1 illustrates this within-subject pain variability, distributed according to the relative time with sustained trapezius muscle activity.

\section{Work-related exposure over time}

The working status, self-reported mechanical workload and control over own work intensity were followed for the whole observation period. The participants working status was rather stable over the study period. After six months, two participants changed status (one electrician became unemployed and one subject working in kindergarten started to study). After one and two years, five participants changed working status (one of the electrician and one of the subjects in other profession started to study, one hairdresser changed occupation and two students started to work). A small but insignificant increase in the self-reported mechanical workload score was found over the 2.5-year period [mean score $\mathrm{Q} 1=10.8, \mathrm{Q} 4=11.2, \mathrm{Q} 7=11.3(\mathrm{P}=0.65)]$. Control over work intensity showed a slight, but significant, increase during the observation period [mean score $\mathrm{Q} 1=2.0$, $\mathrm{Q} 4=2.5, \mathrm{Q} 7=2.5(\mathrm{P}=0.04)]$.

\section{Pain and muscle activity: Iongitudinal analyses}

Unadjusted analyses. The participants with a high level of sustained muscle activity had a rate of neck and shoulder pain twice that of participants with a low level of sustained muscle activity in the long-term effectanalysis (2.5-year follow-up period). The group with a moderate level of sustained muscle activity showed a tendency to have a higher rate of neck and shoulder pain compared to the low-level group, but the results were not statistically significant (table 3 ).

Figure 2 shows the difference between the three muscle activity groups and neck and shoulder pain among men and women over the period. It also illustrates that the association between the levels of sustained muscle activity and neck pain was stronger at the same time and shortly after the muscle activity measurement was done, further decreasing over time.

Adjusted analyses. In the multivariate analyses on the 2.5-year follow-up, a significant association between high level of muscle activity and neck and shoulder pain was found for the whole group after adjusting for time, mechanical workload, control over work intensity, physical activity, tobacco use, prior pain, and gender. Analyses on the long-term effect stratified by gender showed that male participants with a high level of sustained muscle activity had a rate of neck and shoulder pain 6-times higher than participants with a low level of activity. A tendency towards an association between high sustained trapezius muscle activity and occurrence of pain was also seen among female participants (table 3 ). When analyzing the effect over a 2-year follow-up period (Q2-7), excluding the baseline pain measurement and adjusting for prior pain in the multivariate analyses, the results still showed a significant difference between the high- and low-level muscle activity group (IRR $=2.53$ 95\% CI 1.26-5.07, P<0.001). When adjusting for pain at baseline instead of prior pain in the multivariate analyses, however, this association disappeared in the whole group (IRR=1.49 95\% CI 0.79-2.83, $\mathrm{P}=0.21$ ), stratifying by gender gave a tendency of effect for men but not women. Short-term effect analyses of the 0.5 year follow-up (Q1-2), showed a significant difference between the high and low muscle activity groups for both men (IRR=9.57 95\% CI 1.88-48.68, $\mathrm{P}<0.01)$ and women $(\mathrm{IRR}=7.82$ 95\% CI 2.67-22.92, $\mathrm{P}<0.001)$.

In all the analyses, the minimum duration of sustained muscle activity was set at 4 minutes. Using a minimum duration of 2, 6, 8, and 10 minutes gave similar results. However, choosing a minimum duration of 15 minutes or including all episodes with elevated muscle activity regardless of the length of the episodes ( $>1.6$ seconds) did not result in significant associations with neck and shoulder pain. All the analyses were done using sustained muscle activity divided into three groups. Small changes in the cut-off points did not change the results in a substantial way when dividing the three groups. The results were not substantially altered either by dichotomizing the vari- 
Table 2. Participant characteristics at the time of the EMG recording (Q1), divided into three levels of sustained trapezius muscle activity (low, moderate and high).

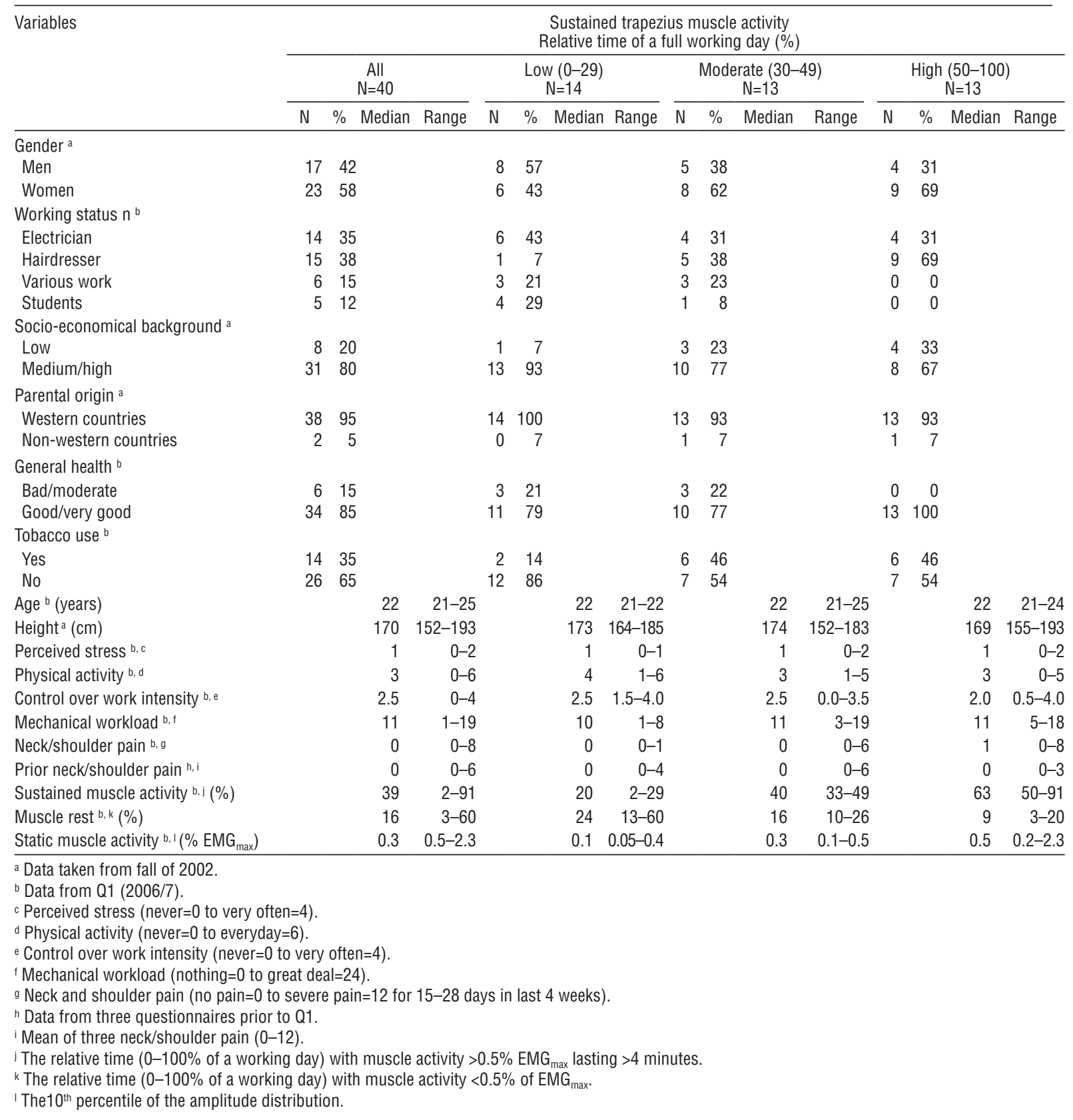

able in a low $(0-39 \%)$ and high group $(40-100 \%)$ or by using the continuous variable $(0-100 \%)$ (IRR $=1.0195 \%$ CI $1.00-1.03, \mathrm{P}=0.01$ ). If the EMG measure static muscle activity was used in the analysis, no significant association with pain was found (IRR=1.36 95\% CI 0.62-3.02, $\mathrm{P}=0.44$ ). Muscle rest showed borderline significant association with reduced neck and shoulder pain (IRR $=0.97$ 95\% CI $0.95-0.99, \mathrm{P}=0.05)$. Static muscle activity and muscle rest were both found to be highly correlated to the sustained muscle activity measure (Spearman's correlation coefficient: 0.82 and -0.79 , respectively).

\section{Discussion}

Measured on a single working day, trapezius muscle activity pattern, with sustained activity for $>4$-minute episodes, was associated with neck and shoulder pain the following 2.5 years. Participants with a high level of sustained muscle activity (50-100\%) during their working day had a rate of neck and shoulder pain during a 2.5-year period 3-times higher than participants with low sustained muscle activity $(<30 \%)$. When stratified 


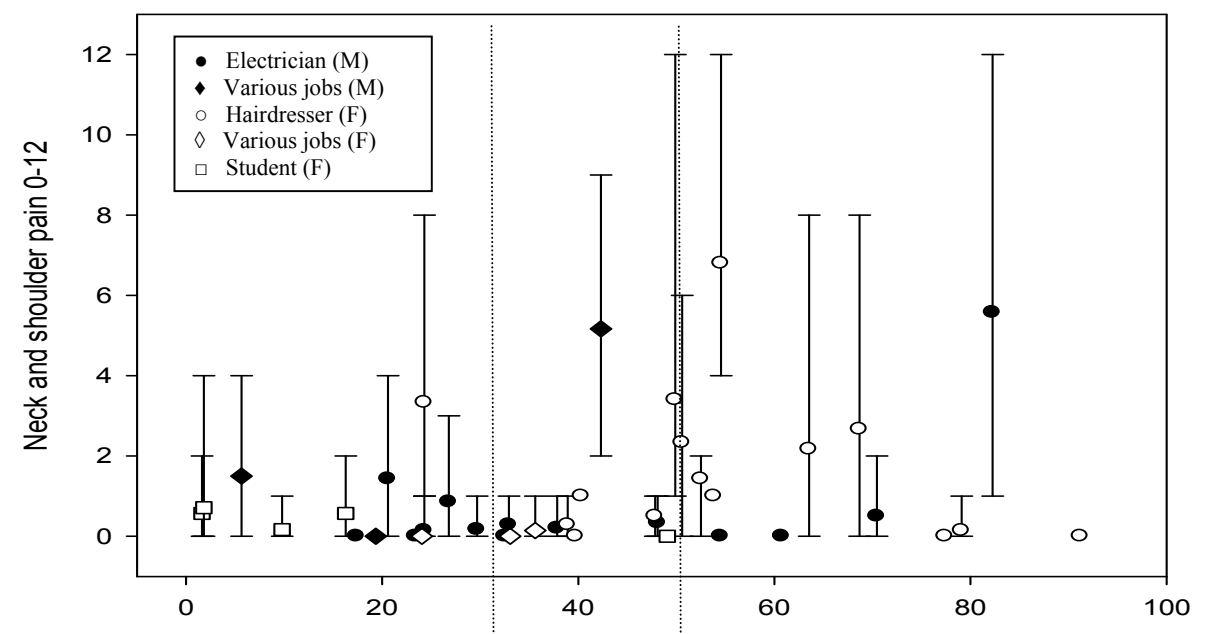

Relative time with sustained trapezius muscle activity with duration of $>4 \mathrm{~min}(0-100 \%)$

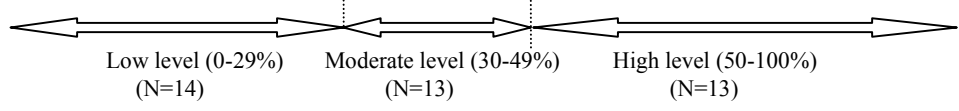

Figure 1. Individual reports of neck and shoulder pain related to sustained muscle activity over a 2.5-year period [questionnaires 1-7 (Q1-7)] indicating median, minimum and maximum values. The sustained trapezius muscle activity is measured at Q1. Gender and occupational groups are also illustrated.

Table 3. The univariate and multivariate generalized estimating equations (GEE) analyses a of the association between neck and shoulder pain and sustained trapezius muscle activity (Q1-7, 2.5 years). [IRR=incidence rate ratio; $95 \% \mathrm{Cl}=95 \%$ confidence interval]

\begin{tabular}{|c|c|c|c|c|c|c|c|c|c|}
\hline \multirow[t]{3}{*}{ Neck and shoulder pain } & \multicolumn{3}{|c|}{ All $(\mathrm{N}=40)$} & \multicolumn{3}{|c|}{ Men $(\mathrm{N}=17)$} & \multicolumn{3}{|c|}{ Women $(\mathrm{N}=23)$} \\
\hline & \multicolumn{3}{|c|}{ N observations $=280$} & \multicolumn{3}{|c|}{ N observations $=119$} & \multicolumn{3}{|c|}{ N observations=161 } \\
\hline & IRR & $95 \% \mathrm{Cl}$ & P-value & IRR & $95 \% \mathrm{Cl}$ & P-value & IRR & $95 \% \mathrm{Cl}$ & P-value \\
\hline \multicolumn{10}{|l|}{ Unadjusted analyses } \\
\hline \multicolumn{10}{|l|}{ Sustained muscle activity } \\
\hline Moderate level & 1.32 & $0.56-3.12$ & 0.53 & 2.05 & $0.48-8.82$ & 0.33 & 0.87 & $0.36-2.07$ & 0.75 \\
\hline High level & 2.64 & $1.28-5.44$ & $<0.01$ & 3.93 & $1.18-13.06$ & 0.02 & 1.94 & $0.80-4.72$ & 0.14 \\
\hline \multicolumn{10}{|l|}{ Adjusted analyses } \\
\hline \multicolumn{10}{|l|}{ Sustained muscle activity } \\
\hline Moderate level & 1.67 & $0.75-3.72$ & 0.21 & 2.59 & $0.93-7.15$ & 0.07 & 1.18 & $0.54-2.63$ & 0.67 \\
\hline High level & 2.89 & $1.45-5.79$ & $<0.01$ & 6.49 & $1.91-22.07$ & $<0.01$ & 1.95 & $0.93-3.66$ & 0.08 \\
\hline
\end{tabular}

by gender, this association was significant among men, and a tendency was also seen among women. The association between sustained muscle activity and pain were strongest at the same time and shortly after the EMG measurement among both genders.

The strengths of this study were the use of longitudinal design, frequent reports of neck and shoulder pain, and an objective measure of vocational muscle activity. This improved the internal validity and limited the possibility of differential misclassification. The longitudinal design increased the number of total observations [7 observations per subject $(40)=280$ observations], which improved the statistical power in spite of a small number of subjects. The small number of subjects may nevertheless increase the uncertainty in the estimates, ie, when analyzing the 0.5 -year follow-up. The partici- pants constituted a subsample of a cohort of 420 young adults and analysis showed no significant differences in the relevant variables between the subsample and the rest of the cohort. Thus, the participants seemed to be representative of the cohort.

Measuring muscle activity on at least two full working days has been proposed as optimal $(37,38)$, but we were only able to achieve one recording, decreasing the reliability of this exposure measurement. The work tasks of hairdressers and electricians, however, can be considered as being rather similar from day to day, and how they work is likely to be largely habitual. Only two of the subjects changed their vocational status during the first six months. Repeated recordings of vocational muscle activity during a one-year period (39) and several recordings during one week (40) have also shown a stable 


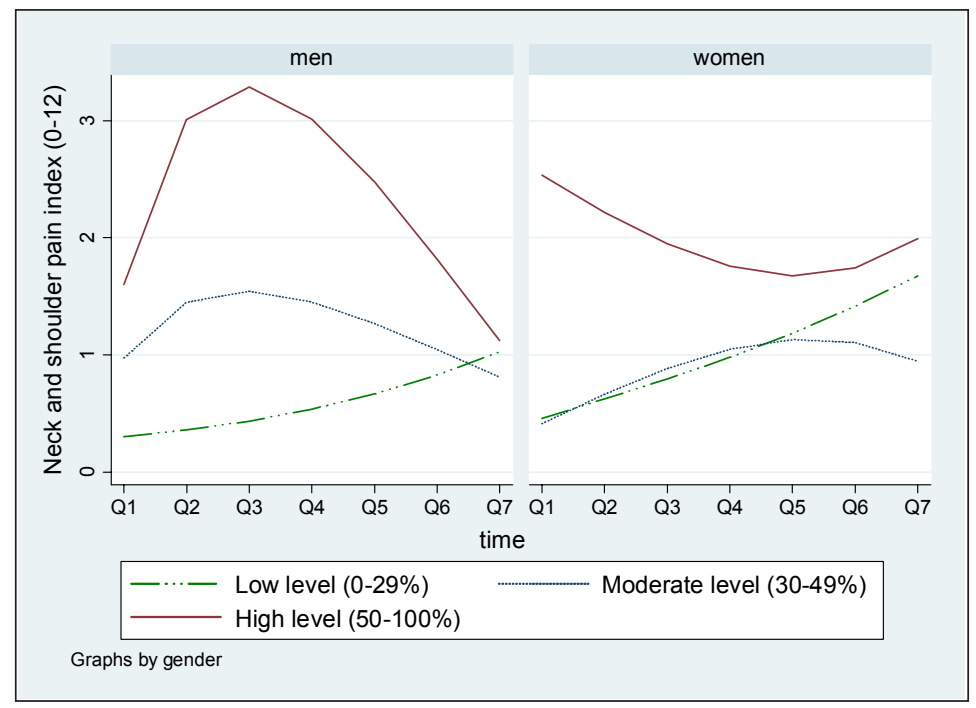

Figure 2. Neck and shoulder pain development divided into three groups depending on level of sustained trapezius muscle activity by gender [men $(\mathrm{N}=17)$ and women $(\mathrm{N}=23)]$. Univariate associations over a 2.5-year period [questionnaires 1-7 (Q1-7)]. within-subject motor pattern when evaluating a specific work situation. This makes the use of muscle activity measurements from a single working day reasonable as representative for the individual exposure estimate.

Large within-subject variability in neck and shoulder pain was found while the pain on a group level was rather stable. These findings are consistent with a study of healthy service-sector workers followed with monthly complaint reports over a 3-year period (26) and among female industrial workers (39). This fluctuation in individual pain over time shows the importance of using a longitudinal design with frequent follow-ups when evaluating pain association.

The relative time of sustained muscle activity was divided in three equally sized groups (low, moderate, and high) to evaluate a possible dose-response effect. The limits for these three groups were determined by the distribution within the sample and not biological arguments. Different cut-offs or the use of a continuous exposure variable showed similar results, indicating a robust measure.

In our analyses, the length of muscle activity was set at $>4$ minutes, however using 2, 6, 8, and 10 minutes as the minimum duration of sustained muscle activity gave similar results. The lack of significant association between duration of sustained muscle activity $>15$ minutes and pain was explained by the low statistical power when only a few recordings included those long episodes. In the study of Østensvik et al (23), the risk of later neck pain was significantly increased for subjects with sustained muscle activity episodes lasting $>8$ minutes. This was partly in agreement with our data, but our results suggest that an association to pain may be relevant also for durations shorter than 8 minutes (ie, $>2$ minutes). Østensvik et al (23) also found reduced risk for future neck pain among the subjects with sustained muscle activity episodes of much shorter duration (ie, $<2$ minutes). In accordance with these findings, our results show the total relative time with sustained activity including all episode durations (an almost reciprocal parameter to muscle rest) has no association with pain. This may be explained by the fact that the number of short episodes of muscle activity (and rest) lasting $<2$ minutes vastly outnumbers those of longer duration. This shows that the analysis of sustained muscle activity may include an evaluation of both very short episodes with activity/rest, constituting a beneficial muscle activity pattern, and longer episodes that possibly have the opposite effect. The pattern of these short and long episodes of activity may therefore be important determinants of conditions in the muscle related to pain development.

Sustained muscle activity has been hypothesized to be a mechanism for pain development in low-level forcedemanding work $(9,41,42)$ with focus on the possible predictive feature of the temporal aspect of activity and rest. The proportion of time with muscle rest $(43,44)$ and the total relative time with episodes of sustained muscle activity $(45,46)$ both capture the temporal aspect of muscle activity. These methods, however, produce a description of the average time with sustained muscle activity while disregarding the duration of activity episodes. To our knowledge there has only been one earlier study incorporating the duration of sustained muscle activity episodes (23). This study showed that sustained muscle activity of $>8$ minutes duration could be an important risk factor for neck pain, which is in agreement with our findings. For reasons stated in the Methods section, we chose a duration limit of $>4$ minutes in our main analysis. However, analyzing our data with a duration limit of $>8$ 
minutes would not haved changed our conclusions.

An increased rate of neck and shoulder pain among subjects with a high level of sustained muscle activity was found both with the use of pain at baseline, prior pain, and longitudinal analysis adjusting for prior pain. This was consistent with other cross-sectional and longitudinal studies, which showed that workers with or contracting neck and shoulder pain had lower frequency of interruptions of sustained muscular activity (47), less muscle rest $(43,44)$, higher static activity level (48), or more bursts of muscle activity (46), compared to healthy controls.

Our results are in contrast to findings from other studies showing no difference in EMG activity patterns between workers with and without pain (14-16). These discrepancies may be partly explained by methodological differences. Recording time differences, the use of laboratory recordings with work simulation versus field registrations, and differences in EMG data reduction methods made it difficult to compare our findings with earlier studies (14-16). To facilitate a comparison, an analysis of static muscle activity was conducted and showed no association with neck and shoulder pain. This is also in accordance with findings in an earlier study (49). Static muscle activity is one of the EMG measures that has been extensively studied. However, it disregards the temporal pattern of the activity, and it has been debated that the lack of association with neck pain may be due to the importance of the temporal aspect of the exposure (50).

The results showing that the pain evaluated during the last four weeks at baseline was related to sustained muscle activity at the same time-point, indicate that pain and sustained muscle activity were reciprocally linked, as explained by Travell (51) and later refined as the "vicious cycle hypothesis" (52). This hypothesis does not seem to explain the initiation of pain, but merely the sustainment of the problem. On the basis of this study it was, however, not possible to determine which comes first or where the circle begins. When adjusting for prior pain in the multivariate analysis, significant associations suggest that there is an independent effect of sustained muscle activity on later neck and shoulder pain. The results were somewhat altered when adjusting for pain at baseline instead of prior pain in the multivariate analyses where the association disappeared in the whole group. This finding and the strong association with neck and shoulder pain in the cross-sectional and short-term analysis ( 0.5 year follow-up) indicates that a time-lag of $\leq 6$ months from exposure to effect may be reasonable.

Our study showed gender differences in the association between muscle activity and pain. Among the male participants, we found a significantly higher rate of neck and shoulder pain for the group with a high level of sustained muscle activity. For women, there was only a tendency towards association between sustained muscle activity and pain. Some claim womens' higher vulner- ability explains gender differences in pain reports (53), but a recent longitudinal study supports our findings, reporting that men had a higher risk of musculoskeletal symptoms than women after equal exposure (54). The women in our study also had a higher pain level from the start, giving them less room for a pain increase compared to the men. It is however important to be aware that sustained trapezius muscle activity may be influenced by individual muscular tension or postural motor habits as well as the external mechanical workload. The gender difference may also be explained by the occupational differences between the genders, since most of the females were hairdressers and most of the male participants were electricians. Analyzing hairdressers and electricians separately also showed the same result, indicating that the gender difference could be partly explained by the occupational status. However, because of the co-linearity, it was hard to draw conclusions on both gender and occupation.

In conclusion the results strengthen the hypothesis that sustained trapezius muscle activity is associated with neck and shoulder pain. With considerations to the methodological limitations, our study implicates that sustained muscle activity episodes lasting $>4$ minutes for more than half of the working day increases the rate of neck and shoulder pain. This association was strongest when analyzing cross-sectional and short-term effects.

\section{References}

1. Buckle PW, Devereux JJ. The nature of work-related neck and upper limb musculoskeletal disorders. Appl Ergonomics. 2002;33:207-17. http://dx.doi.org/10.1016/ S0003-6870(02)00014-5

2. Punnett L, Wegman DH. Work-related musculoskeletal disorders: the epidemiologic evidence and the debate. J Electromyogr Kinesiol. 2004;14(1):13-23. http://dx.doi. org/10.1016/j.jelekin.2003.09.015.

3. Hanvold TN, Veiersted KB, Wærsted M. A prospective study of neck, shoulder and upper back pain among technical school students entering working life. J Adolesc Health. 2010;46:488 94. http://dx.doi.org/10.1016/j.jadohealth.2009.11.200.

4. Côté P, van der Velde G, Cassidy JD, Carroll LJ, Hogg-Johnson $\mathrm{S}$, Holm LW et al. The burden and determinants of neck pain in workers: results of the Bone and Joint Decade 2000-2010 Task Force on Neck Pain and Its Associated Disorders. Spine. 2008;33 Suppl 4:S60-74. http://dx.doi.org/10.1097/ BRS.0b013e3181643ee4.

5. Wahlström J, Hagberg M, Toomingas A, Wigaeus Tornqvist E. Perceived muscular tension, job strain, physical exposure, and associations with neck pain among VDU users; a prospective cohort study. Occup Environ Med. 2004;61(6):523-8. http:// dx.doi.org/10.1136/oem.2003.009563. 
6. Christensen JO, Knardahl S. Work and neck pain: a prospective study of psychological, social, and mechanical risk factors. Pain. 2010;151(1):162-73. http://dx.doi.org/10.1016/j. pain.2010.07.001

7. Cagnie B, Danneels L, Van Tiggelen D, De Loose V, Cambier D. Individual and work related risk factors for neck pain among office workers: a cross sectional study. Eur Spine J. 2007;16(5):679-86. http://dx.doi.org/10.1007/s00586-0060269-7.

8. Cassou B, Derriennic F, Monfort C, Norton J, Touranchet A. Chronic neck and shoulder pain, age, and working conditions: longitudinal results from a large random sample in France. Occup Environ Med. 2002;59:537-44. http://dx.doi. org/10.1136/oem.59.8.537.

9. Sjøgaard G, Lundberg U, Kadefors R. The role of muscle activity and mental load in the development of pain and degenerative processes at the muscle cell level during computer work [Editorial]. Eur J Appl Physiol. 2000;83(23):99-105. http://dx.doi.org/10.1007/s004210000285.

10. Veiersted KB, Westgaard RH. Development of trapezius myalgia among female workers performing light manual work. Scand J Work Environ Health. 1993;19(4):277-83. http:// dx.doi.org/10.5271/sjweh.1473.

11. Szeto GPY, Straker LM, O'Sullivan PB. A comparison of symptomatic and asymptomatic office workers performing monotonous keyboard work--1: neck and shoulder muscle recruitment patterns. Man Ther. 2005;10(4):270-80. http:// dx.doi.org/10.1016/j.math.2005.01.004.

12. Østensvik T, Veiersted KB, Nilsen P. Association between number of long periods with sustained low-level trapezius muscle activity and neck pain. Ergonomics. 2009;52(12):155667. http://dx.doi.org/10.1080/00140130903199889.

13. Lund JP, Donga R, Widmer CG, Stohler CS. The pain-adaption model: a discussion of the relationship between chronic musculoskeletal pain and motor activity. Can J Physiol Pharmacol. 1991;(69):683-94. http://dx.doi.org/10.1139/ y91-102.

14. Takala EP, Viikari-Juntura E. Muscle force, endurance and neck-shoulder symptoms of sedentary workers. An experimental study on bank cashiers with and without symptoms. Int J Industrial Ergonomics. 1991;7:123-32. http:// dx.doi.org/10.1016/0169-8141(91)90043-L.

15. Jensen C, Nilsen K, Hansen K, Westgaard RH. Trapezius muscle load as a risk indicator for occupational shoulder- neck complaints. Int Arch Occup Environ Health. 1993;64(6):41523. http://dx.doi.org/10.1007/BF00517947.

16. Vasseljen O, Westgaard RH. Can stress-related shoulder and neck pain develop independently of muscle activity? Pain. 1996;64(2):221-30. http://dx.doi.org/10.1016/03043959(95)00103-4.

17. Westgaard RH. Effects of physical and mental stressors on muscle pain. Scandin J Work Environ Health. 1999;25 Suppl 4:S19-24.

18. Østerås N, Ljunggren AE, Gould KS, Wærsted M, Veiersted KB. Muscle pain, physical activity, self-efficacy and relaxation

ability in adolescents. Advances in Physiotherapy. 2006;(8):3340. http://dx.doi.org/10.1080/14038190600565093.

19. Mathiassen SE, Winkel J, Hägg GM. Normalization of surface EMG amplitude from the upper-trapezius muscle in ergonomic studies - a review. J Electromyogr Kinesiol. 1995;5(4):197226. http://dx.doi.org/10.1016/1050-6411(94)00014-X.

20. Veiersted KB. The reproducibility of test contractions for calibration of electromyographic measurements. Eur J Appl Physiol. 1991;62:91-8. http://dx.doi.org/10.1007/ BF00626762.

21. Hansson GÅ, Asterland P, Skerfving S. Acquisistion and analysis of whole-day electromyographic field recordings. In: Hermens HJ, Hägg G, Freriks B, editors. Proceedings of the second general SENIAM Workshop; 1997 June 12-15; Stockholm, Sweden. 1997. p. 19-27.

22. Veiersted KB, Forsman M, Hansson GÅ, Mathiassen SE. Assessment of time patterns of activity and rest in full-shift recordings of trapezius muscle activity - Effects of the data processing procedure. J Electromyogr Kinesiol. 2013 Jan 30. [Epub ahead of print] http://dx.doi.org/10.1016/j. jelekin.2012.12.004.

23. Østensvik T, Veiersted KB, Nilsen P. A method to quantify frequency and duration of sustained low-level muscle activity as a risk factor for musculoskeletal discomfort. J Electromyogr Kinesiol. 2009;19(2):283-94. http://dx.doi.org/10.1016/j. jelekin.2007.07.005.

24. Jonsson B. Measurement and evaluation of local muscular strain in the shoulder during constrained work. J Hum Ergol. 1982;(11):73-88.

25. Veiersted KB, Westgaard RH, Andersen P. Pattern of muscle activity during stereotyped work and its relation to muscle pain. Int Arch Occup Environ Health. 1990;(62):31-41. http:// dx.doi.org/10.1007/BF00397846.

26. Steingrímsdóttir ÓA, Vøllestad NK, Røe C, Knardahl S. Variation in reporting of pain and other subjective health complaints in a working population and limitations of single sample measurements. Pain. 2004;110(1-2):130-9. http:// dx.doi.org/10.1016/j.pain.2004.03.016.

27. Kuorinka I, Jonsson B, Kilbom Å, Vinterberg H, BieringSørensen F, Andersson G et al. Standardised Nordic questionnaires for the analysis of musculoskeletal symptoms. Appl Ergonomics. 1987;18(3):233-7. http://dx.doi. org/10.1016/0003-6870(87)90010-X.

28. Steingrímsdóttir ÓA. Subjective health complaints and their relation to muscle responses in a working population [dissertation]. Oslo, Norway: Faculty of Medicine, University of Oslo and National Institute of Occupational Health; 2005.

29. Dallner M, Elo A-L, Gamberale F, Hottinen V, Knardahl S, Lindstrøm K, et al. Validation of the General Nordic Questionnaire for Psychological and Social Factors at Work. Copenhagen: Nordic Council of Ministers, Nord; 2000. p. 12.

30. Balogh I, Ørbæk P, Winkel J, Nordander C, Ohlsson K, EktorAndersen $\mathrm{J}$ et al. Questionnaire-based mechanical exposure indices for large population studies - reliability, internal consistency and predictive validity. Scand J Work Environ Health. 2001;27(1):41-8. http://dx.doi.org/10.5271/sjweh.585. 
31. Wold B, Hetland J, Aarø LE, Samdal O, Torsheim T. Utviklingstrekk i helse og livsstil blant barn og unge fra Norge, Sverige, Ungarn, og Wales [Trends in health and lifestyle in children and adolescents in Norway, Sweden, Hungary and Wales. Results from nationwide surveys in health behavior in school-aged children, a WHO cross-national study]. HEMIL report no 1. Bergen: Research Centre for Health Promotion, University of Bergen, 2000.

32. Spratt M, Carpenter J, Sterne JAC, Carlin JB, Heron J, Henderson $J$ et al. Strategies for multiple imputation in longitudinal studies. Am J Epidemiol. 2010;172(4):478-87. http://dx.doi.org/10.1093/aje/kwq137.

33. Rubin DB. Multiple imputation after $18+$ years. Journal of the American Statistical Association. 1996;91(434):473-89. http://dx.doi.org/10.1080/01621459.1996.10476908.

34. Baraldi AN, Enders CK. An introduction to modern missing data analyses. J Sch Psychol. 2010;48(1):5-37. http://dx.doi. org/10.1016/j.jsp.2009.10.001.

35. Zeger SL, Liang KY. Longitudinal data analysis for discrete and continuous outcomes. Biometrics. 1986;42(1):121-30. http://dx.doi.org/10.2307/2531248.

36. Zeger SL, Liang KY, Albert PS. Models for longitudinal data: a generalized estimating equation approach. Biometrics. 1988;44(4):1049-60. http://dx.doi.org/10.2307/2531734.

37. Nordander C, Balogh I, Mathiassen SE, Ohlsson K, Unge J, Skerfving S et al. Precision of measurements of physical workload during standardised manual handling. Part I: surface electromyography of $\mathrm{m}$. trapezius, $\mathrm{m}$. infraspinatus and the forearm extensors. J Electromyogr Kinesiol. 2004;14(4):44354. http://dx.doi.org/10.1016/j.jelekin.2003.12.003.

38. Delisle A, Larivière C, Imbeau D, Durand MJ. Physical exposure of sign language interpreters: baseline measures and reliability analysis. Eur J Appl Physiol. 2005;94(4):448-60. http://dx.doi.org/10.1007/s00421-005-1316-5.

39. Veiersted KB, Westgaard RH, Andersen P. Electromyographic evaluation of muscular work pattern as a predictor of trapezius myalgia. Scand J Work Environ Health. 1993;19(4):284-90. http://dx.doi.org/10.5271/sjweh.1472.

40. Veiersted KB. Reliability of myoelectric trapezius muscle activity in repetitive light work. Ergonomics. 1996;39(5):797807. http://dx.doi.org/10.1080/00140139608964499.

41. Hägg GM. Static work loads and occupational myalgia - a new explanation model. In:Anderson PA, Hobart DJ, Danoff JV, editors. Electromyographical kinesiology. Amsterdam: Elsevier; 1991:141-3.

42. Madeleine P. On functional motor adaptations: from the quantification of motor strategies to the prevention of musculoskeletal disorders in the neck-shoulder region. Acta Physiol. 2010;199 Suppl 679:S1-46. http://dx.doi. org/10.1111/j.1748-1716.2010.02145.x.

43. Sandsjö L, Melin B, Rissén D, Dohns I, Lundberg U. Trapezius muscle activity, neck and shoulder pain, and subjective experiences during monotonous work in women. Eur J Appl Physiol. 2000;83(2-3):235-8. http://dx.doi.org/10.1007/ s004210000284.

44. Thorn S, Søgaard K, Kallenberg LAC, Sandsjö L, Sjøgaard $\mathrm{G}$, Hermens $\mathrm{HJ}$ et al. Trapezius muscle rest time during standardised computer work - a comparison of female computer users with and without self-reported neck/shoulder complaints. J Electromyogr Kinesiol. 2007;17(4):420-7. http://dx.doi.org/10.1016/j.jelekin.2006.04.010.

45. Mathiassen SE, Winkel J. Quantifying variation in physical load using exposure-vs-time data. Ergonomics. 1991;34(12):145568. http://dx.doi.org/10.1080/00140139108964889.

46. Mork PJ, Westgaard RH. Low-amplitude trapezius activity in work and leisure and the relation to shoulder and neck pain. J Appl Physiol. 2006;100(4):1142-9. http://dx.doi.org/10.1152/ japplphysiol.01111.2005.

47. Aarås A. Relationship between trapezius load and the incidence of musculoskeletal illness in the neck and shoulder. Int J Industrial Ergonomics. 1994;(14):341-8.

48. Finsen L, Christensen H, Bakke M. Musculoskeletal disorders among dentists and variation in dental work. Applied Ergonomics. 1998;29(2):119-25. http://dx.doi.org/10.1016/ S0003-6870(97)00017-3.

49. Westgaard RH, Vasseljen O, Holte KA. Trapezius muscle activity as a risk indicator for shoulder and neck pain in female service workers with low biomechanical exposure. Ergonomics. 2001;44(3):339-53.

50. Mathiassen SE. Diversity and variation in biomechanical exposure: what is it, and why would we like to know? Appl Ergon. 2006;37(4):419-27. http://dx.doi.org/10.1016/j. apergo.2006.04.006.

51. Travell JG, Rinzler S, Herman M. Pain and disability of the shoulder and arm. JAMA. 1942;(120):417-22. http://dx.doi. org/10.1001/jama.1942.02830410005002.

52. Johansson H, Sojka P. Pathophysiological mechanisms involved in genesis and spread of muscular tension in occupational muscle pain and in chronic musculoskeletal pain syndromes: a hypothesis. Med Hypotheses. 1991;(35):196203. http://dx.doi.org/10.1016/0306-9877(91)90233-O.

53. Strazdins L, Bammer G. Women, work and musculoskeletal health. Soc Sci Med. 2004;(58):997-1005. http://dx.doi. org/10.1016/S0277-9536(03)00260-0.

54. Hooftman WE, van der Beek AJ, Bongers PM, van Mechelen $\mathrm{W}$. Is there a gender difference in the effect of work-related physical and psychosocial risk factors on musculoskeletal symptoms and related sickness absence? Scand J Work Environ Health. 2009;35(2):85-95. http://dx.doi.org/10.5271/ sjweh.1316.

Received for publication: 23 October 2012 